\title{
КОМПЛЕКСНОЕ ИССЛЕДОВАНИЕ ФИЗИОЛОГИЧЕСКИХ, МОРФОМЕТРИЧЕСКИХ ПОКАЗАТЕЛЕЙ И ЭЛЕМЕНТНОГО СОСТАВА ЛИСТЬЕВ ВИДА ОLЕA EUROPЕA L. В КОНТЕКСТЕ ГОРОДСКОЙ ЭКОСИСТЕМЫ
}

\section{COMPLEX INVESTIGATION OF PHYSIOLOGICAL, MORPHOMETRIC PARAMETERS AND THE ELEMENTAL COMPOSITION IN LEAVES \\ OF THE SPECIES OLEA EUROPEA \\ L. IN THE CONTEXT OF THE URBAN ECOSYSTEM}

\section{B. Gafarova}

A. Mamedova

R. Mamedova

Summary. The research was conducted to define the phyto-indicative and phytoremediative properties of the olive tree Olea europea L., which is widely distributed in the Baku city, the capital of the Republic of Azerbaijan, characterized by a tense ecological state. For an integral ecological assessment of the urban environment polluted by anthropogenic factors, chlorophyll fluorescence, fluctuating asymmetry, elemental analysis of the leaves of 0 . europea were studied in parallel, and the correlation between them was determined. A comparative analysis of the physiological state, phenotypic changes in morphological signs, and properties of metal accumulation in the leaves of 0 . europea was carried out, and the ecological basis of the use of this plant in environmental monitoring was also indicated.

Keywords: fitomonitoring, morphological signs, physiological state, elemental analysis.

\section{Вступление}

A пшеронский экономический район Азербайджана особо нуждается в охране зеленых насаждений. Возрастающее число городского населения, а также параллельное возрастание количество автотранспорта и других техногенных загрязнений, существенно увеличило нарушение баланса между обществом и окружающей средой. В урбанизированных регионах одной из приоритетных направлений является охрана окружающей среды. Так, промышленные предприятия, техногенные загрязнения негативно влияют на биоразнообразие, регулярно подвергая раститель-
Гафарова Беим Таир кызы

Докторант, Бакинский Государственный Университет, г. Баку

bayimgafarova@gmail.com

Мамедова Афет Октай кызы

Д.б.н., профессор, Бакинский Государственный

Университет, г. Баку

m.afet@mail.ru

Мамедова Роза Назим кызы

Докторант, Бакинский Государственный

Университет, г. Баку

roza2919@mail.ru

Аннотация. Исследования проведены с целью определения фитоиндикативных и фиторемедиативных свойств оливкового дерева - Olea europea L., широко распространенного в характеризующимся напряженным экологическим состоянием городе Баку, столице Азербайджанской Республики. Для интегральной экологической оценки загрязненной антропогенными факторами городской среды, были исследованы параллельно флуоресценция хлорофилла, флуктуирующая асимметрия, элементный состав листьев 0. europea, и определена корреляционная зависимость между ними. Проведен сопоставительный анализ физиологического состояния, фенотипических изменений морфологических признаков и свойств накопления металлов в листьях 0.europea., а также указаны экологические основы использования этого растения в экологическом мониторинге.

Ключевые слова: фитомониторинг, морфологические признаки, анализ физиологического состояния, элементный анализ.

ные ресурсы постепенной деградации, приводя к образованию экологически опасных участков. В результате многолетней интенсивной деятельности человека произошло изменение оптимального состояния лесов, озеленений, что послужило существенному сокращению биоразнообразия. Основной целью в данном случае является проведение экологического мониторинга, для своевременного предотвращения уничтожения зеленых массивов и предварительного планирования прогнозов. Актуальным вопросом в экологическом мониторинге является разработка методов ранней диагностики. Для чего необходимо определение нарушения биоиндикативных показателей зеленых массивов, 
выявление ПДК загрязнителей для исследуемых растений, а также разработка планированного прогнозирования изменения состояния древесной растительности В результате кратковременного и долговременного интенсивного антропогенного воздействия. В связи с тем, что растительные объекты составляют большую часть биомассы экосистемы, они являются более приемлимыми в проведении экологического мониторинга. По сравнению с другими живыми организмами, растения наиболее уязвимы, подвержены воздействию вредных факторов среды и могут подвергаться изменениям на уровне организма, органов и клеток [13]. Древесная растительность, выступая индикаторами в биомониторинге, позволяет более информативно исследовать годовые сезонные изменения среды [6]. При исследовании влияния вредных факторов окружающей среды на растения изучаются морфологические структуры и физиологические процессы листьев, как относительно наиболее чувствительных тканей и органов растительного организма, находящихся в более тесном контакте с окружающей средой. Изучение условий загрязненной среды, основано на исследовании фенотипических отклонений изучаемых морфологических признаков растительных организмов на уровне тканей, биоиндикации [4]. К отклонениям морфологических признаков высших растений относится изменение цвета листьев, хлороз, некроз, сморщивание (обезвоживание) листа, выпадение листьев и др. В экофизиологических исследованиях как особые объекты выступают вечнозеленые и листопадные деревья [11].

В литературе достаточно широко известны материалы об изменении показателей флуктуирующей асимметрии листьев растений, как показателя интегральной оценки стабильности развития организмов в онтогенезе под действием факторов риска $[10,14]$. Согласно литературным данным, результаты многочисленных экспериментов показывают, что при различных стрессовых условиях физиологические изменения в листьях растений, особенно в процессе фотосинтеза, который наиболее важен для растений, можно обнаружить с помощью анализа спектров излучения флуоресценции хлорофилла $[2,5]$.

В связи с этим в исследовательской работе для выявления морфо-физиологических изменений у популяций оливковых деревьев, растущих в различных по степени загрязненности территориях города Баку, Апшеронского района, проведен анализ спектров флуоресценции хлорофилла и изучено изменение показателей флуктуирующей асимметрии их листьев. Одновременно для выявления аккумулятивных свойств листьев, были проведены анализы металлов, накопление которых в листьях, является экологически значимой [9]. Итак, для использования в экологическом мониторинге окружающей среды широко распространенного в городе Баку растения оливковое дерево, является важным проведение анализов и наблюдений для характеристики фитоиндикационных и фиторемедиативных свойств этого растения.

В проведенных исследованиях в качестве объекта исследования были использованы листья Olea europea L.- оливкового дерева. O. eиropea является вечнозеленым деревом высотою в 4-6 м, в некоторых случаях и выше с густой кроной. Листья оливы ланцетовидные с серо-зеленой окраской. Данное растение еще с древних времен использовалось для получения растительного масла и в декоративных целях. Оливковое дерево - характерное растение сухих субтропиков, хорошо растущее в условиях континентального климата, устойчивое к засухе, слабому засолению и сильным ветрам. По этой причине в ряде регионов Азербайджана, особенно на Апшеронском полуострове, оливковые деревья широко распространены. Несмотря на то, что $O$. europea является долгожителем и устойчивым растением, оно также может использоваться в качестве объекта биомониторинга [5]. В настоящее время в Апшеронском районе выращивают более 20 сортов оливок, которые встречаются почти на каждом участке Апшеронского полуострова. Поэтому целесообразно использовать ее в биомониторинге и проводить оценку экологического состояния окружающей среды на основе индивидуального устойчивого развития оливковых деревьев.

Исследования проводились в двух различных по степени загрязнения территориях города Баку. Территории исследования были выбраны на основании отчетов Министерства экологии и природных ресурсов и результатов анализа почвы и атмосферного воздуха в соответствующих лабораториях Бакинского Государственного Университета и Института Геологии НАНА. В качестве экологически относительно более чистой оптимальной зоны произрастания оливкового дерева, был выбран участок на территории Ботанического сада в Ясамальском районе города Баку. Как экологически относительно загрязненная зона, был выбран участок в Бинагадинском районе города Баку, вблизи бетон заливного завода, на обочине Бинагадинского шоссе, с интенсивным транспортным потоком. Были исследованы листья оливковых деревьев, растущих на этих участках.

Для анализа показателей флуктирующей асимметрии оливкового дерева с 20 деревьев были взяты порядка 250-300 листьев. Листья были отобраны с четырех сторон кроны оливкового дерева, с высоты 1,31,7 м. В пределах максимальной ширины каждого листка, были измерены расстояния как влево, так и вправо 

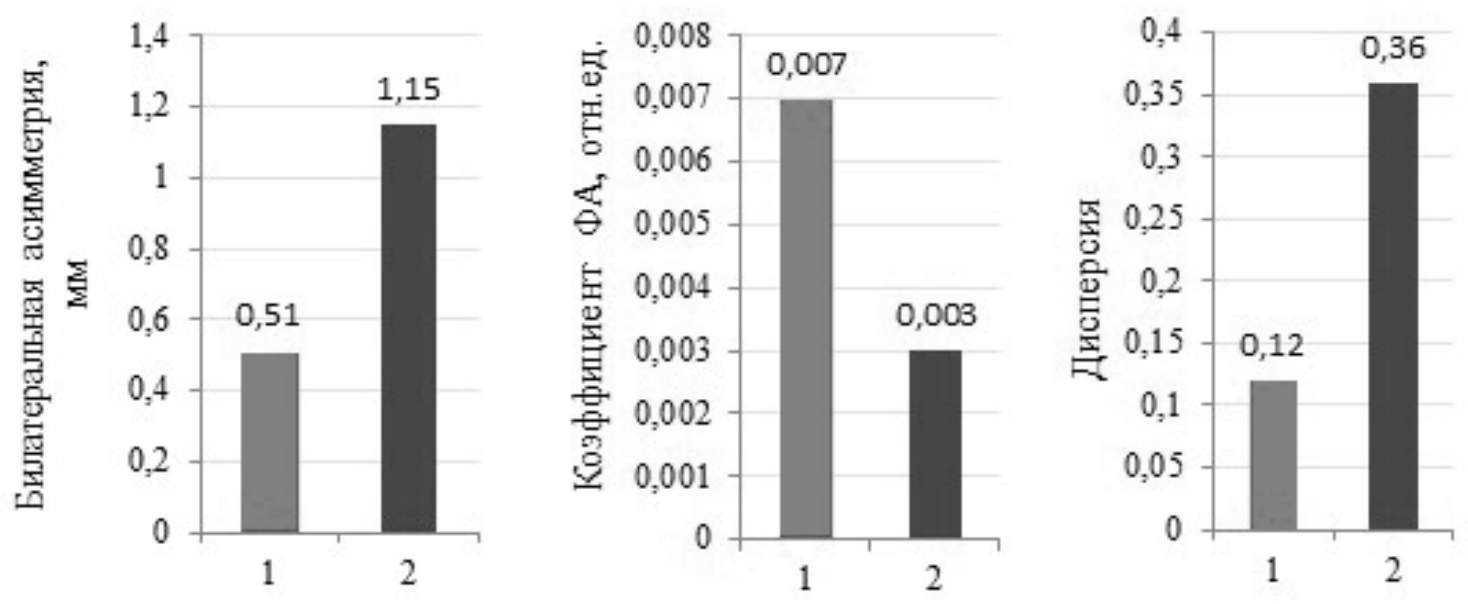

Рис. 1. Интегральные показатели флуктуирующей асимметрии листьев Olea europea L., на территориях 1) экологического оптимума и 2) экологического риска

от центральной жилки (R и L) и длина центральной жилки (I). Для измерений была использована лупа MBS-9 с мм-ым окуляром [7]. Вычисления проводились специальным пакетом программ STATISTIKA 6, созданным на основе языка программирования Java Script (ECMA Script 6). Разработанная программа основана на современном программном обеспечении и вычисления производятся по известным статистическим биометрическим формулам. Были определены показатели флуктуирующей асимметрии листьев - билатеральная разница, среднеквадратичное отклонение, дисперсия, коэффициент флуктуирующей асимметрии, коэффициент вариации, линейное отклонение, вероятность, а распространение билатеральной разницы было показано графически.

В ходе исследования наряду с асимметричными изменениями листьев объектов исследования, был проведен сравнительный анализ также характеристик спектров флуоресценции хлорофилла листьев. регистрируемых при комнатной температуре $\left(20^{\circ} \mathrm{C}\right)$. Спектры флуоресценции хлорофилла в листьях (длина волны возбуждения 487 нм) регистрировались на спектрофлуометре Cary Eclipse (Varian Inc., Les Ulis, France) [3]. Спектры излучения были зарегистрированы в интервале длин волн 650-800 нм. Спектры флуоресценции были зарегистрированы с адаксальной стороны на поверхности диаметром в 6 мм.

Элементный анализ в образцах листьев О. europea и параллельно в образцах почв, взятых из пяти различных точек каждой пробной площадки, проводился методом электронной сканирующей микроскопии под сканирующим электронным микроскопом (СЭМ) JEOL JSM-7600F (Япония). Для элементного анализа в образцах невымытых листьев с помощью СЭМ были сдела- ны срезы в виде дисков диаметром 1 см, которые были высушены в чистой среде, не подвергаясь какому-либо воздействию. Под СЭМ эти диски фиксируются с помощью специального держателя на двухслойном углевом стикере и затем приготовленные образцы в условиях вакуума покрываются ионным опрыскивателем золотом и палладием. В работе представлены многослойные изображения и картирование химических элементов в экспериментальных образцах листьев растений и почвы, зафиксированные при помощи СЭМ.

\section{Результаты и их обсужление}

В исследовании пробная площадка, расположенная на относительно чистой территории города Баку, где практически отсутствуют автотранспорт и объекты индустрии была условно названа экологическим оптимумом. А пробная площадка на обочине шоссе с интенсивным транспортным потоком и вблизи промышленных предприятий была условно названа экологически рискованной территорией.

На рисунке 1 из диаграмм отчетливо видны изменения показателей флуктуирующей асимметрии образцов листьев оливкового дерева на пробных площадок. Так, выявлено, что на относительно загрязненном участке, условно именуемом как территория экологического риска, абсолютный показатель билатеральной разницы в листьях оливкового дерева увеличился в 2,3 раза. Коэффициент вариации на участке экологического оптимума составил 40, а на экологически загрязненном участке 62, что в свою очередь указывает на превосходство в 1,5 раза однородности показателей билатеральной разницы в экологически относительно чистых территориях по сравнению с загрязненными территориями. 

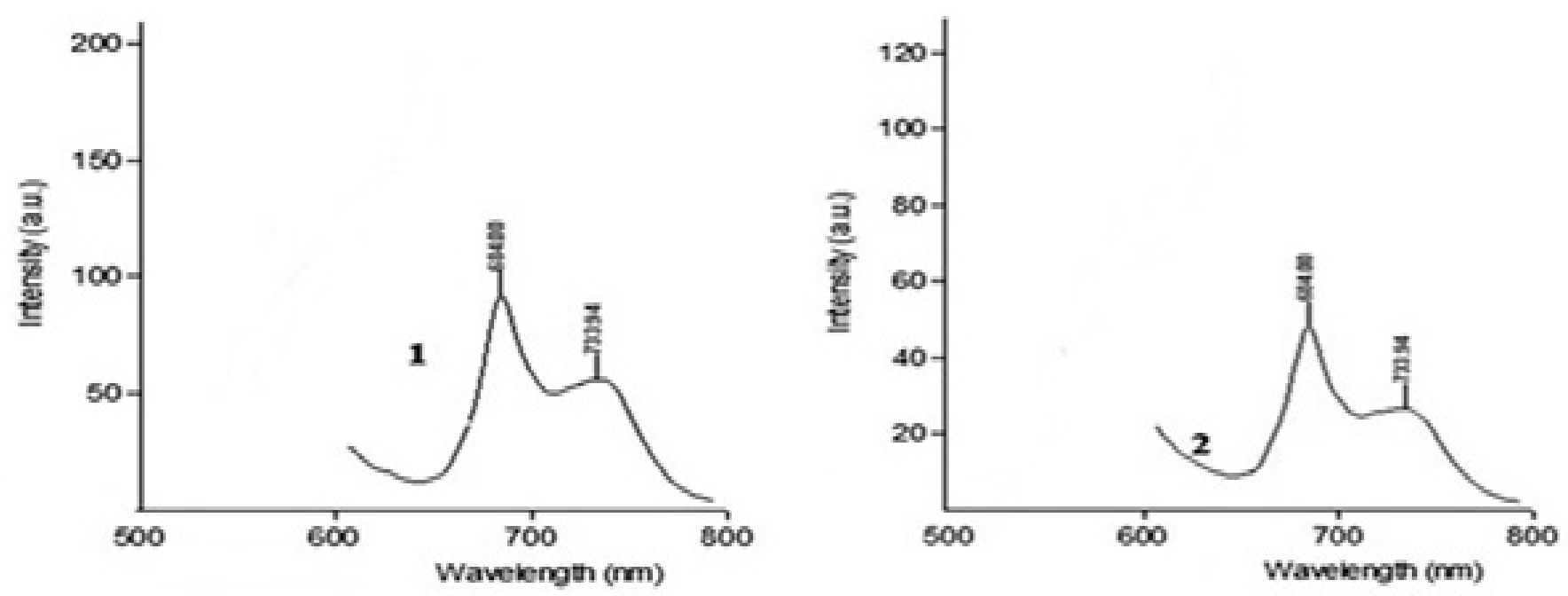

Pис. 2. Спектры флуоресценции хлорофилла в листьях оливки O. europea L. в условиях экологического оптимума (1) и териитории с экологическим риском (2).

Следует отметить, что если в вариационном ряду на участке экологического оптимума в листьях растения доминирующая разница билатеральной асимметрии (Mod) составляет 0,4, то в листьях растений с загрязненного участка она соответствует 0,9. Разница между абсолютным максимумом и минимумом показателей билатеральной асимметрии в рамках вариации, в зоне экологического оптимума равно 2, а в рискованной зоне 3,5. Экологическое состояние относительно экологически чистой территории города Баку оценивается как контрольная в 100 баллов, а исследуемая экологически загрязненная территория согласно результатам и статистическим расчетам оценивается в 61 балл.

Эти показатели, основанные на первичные изменения в живом организме, позволяют оценивать экологическую ситуацию в условиях загрязнения среды. Отмечено, что на территории города Баку, которая считается относительно экологически загрязненной, уровень показателей флуктуирующей асимметрии в листьях оливковых деревьев был выше, чем на экологически оптимальной территории. Возрастание загрязнения окружающей среды и неблагоприятные условия способствуют нарушению стабильного развития оливкового дерева и коррелятивному возрастанию показателей флуктуации.

Для оценки экологического риска параллельно были исследованы характеристики спектров флуоресценции хлорофилла листьев растений. Флуоресцентное излучение хлорофилла является чувствительным параметром к стрессовым воздействиям окружающей среды, поэтому используется в экологической оценке ее состояния $[8,15]$.

Оливковое дерево в настоящее время является широко распространенным деревом на территории Апшерона, в том числе и в городе Баку. Их можно встретить на территориях с различной степенью загрязненности. Рост и развитие оливкового дерева отличается в зависимости от степени загрязненности среды. В экспериментах спектры флуоресценции хлорофилла листьев, собранных с оливкового дерева, растущего на загрязненной территории города Баку, вдоль автомагистралей с интенсивным транспортным потоком и вблизи промышленных предприятий, были сопоставлены с листьями деревьев, растущих в оптимальных условиях.

На рисунке 2 показаны спектры флуоресценции хлорофилла в образцах листьев, собранных на территориях экологического оптимума и экологического риска. Спектры флуоресценции хлорофилла характеризуются на красном участке спектра двумя полосами: коротковолновой полосой с максимумом в 684 нм и относительно слабой, умеренной длинноволновой полосой с максимумом в 734 нм. Как видно из рисунка 2, оба спектра флуоресценции имеют одинакого локализованные максимумы, что показывает относительно слабое воздействие на физиологическое состояние исследуемых растений неблагоприятной окружающей среды.

Интенсивность полос флуоресценции листьев с экологически чистого участка - оптимума, существенно превосходит соответствующие показатели с экологически загрязненных территорий. Разница в интенсивности 

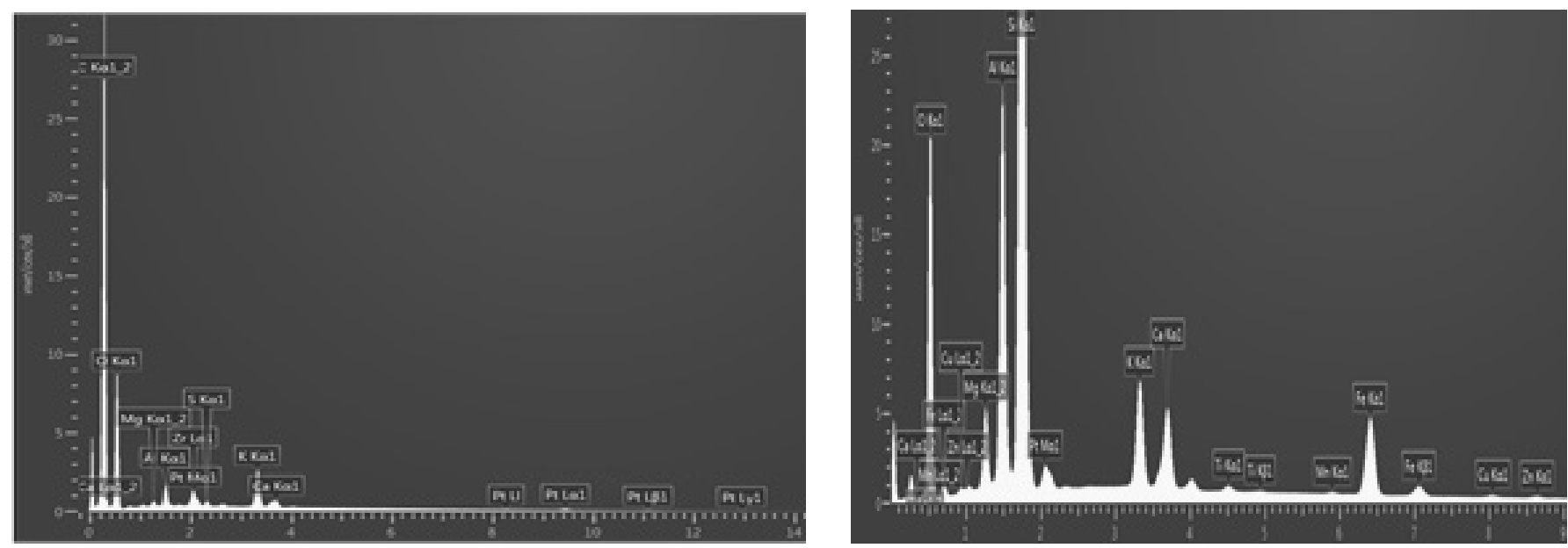

Рис. 3. Картирование элементного состава образцов почв при помощи СэМ: 1) экологический оптимум 2) экологически загрязненная территория

полос флуоресценции вероятно связано с замедлением синтеза свето-аккумулирующего хлорофилл-белкового комплекса и, соответственно, зависит от размеров центра фотосинтетической флуоресценции в листьях оливкового дерева с загрязненных участков. Из данных литературы известно, что отношение коротковолновой максимальной интенсивности флуоресценции хлорофилла к длинноволновой максимальной интенсивности (685/730) способно выступать в качестве основного показателя фотосинтетического аппарата. Из литературных источников известно, что отношение интенсивности максимума коротковолновой флуоресценции хлорофилла к интенсивности длинноволнового максимума (685/730) может выступать как основной показатель фотосинтетического аппарата [12]. Так, данное соотношение на контрольном участке был равно 0,65, а на территории экологического риска составило 0,55. Известно, что коротковолновая полоса флуоресценции в определенной степени рассматривается как излучение тилакоидной мембраны вокруг центра фотосистемы II [1]. Также известно, что фотосистема II считается более чувствительной частью фотосинтетического аппарата к воздействию вредных факторов окружающей среды. Поэтому даже незначительное снижение соотношения Фл $685 / Ф л_{730}$ свидетельствует о снижении активности центра фотосистемы II в листьях деревьев, растущих на загрязненной территории.

Результаты экспериментов показывают, что отличия между спектрами флуоресценции хлорофилла листьев оливковых деревьев с загрязненных территорий и территории экологического оптимума незначительные. Таким образом, оливковые деревья способны сохранять свой нормальный хлорофилловый состав в условиях загрязнения среды и не претерпевают существенных изменений.
В заключение можно отметить, что, хотя оливковое дерево является устойчивым растением, параметры флуоресцентного излучения в его листьях могут быть использованы в качестве компонента экологического мониторинга окружающей среды и могут быть полезны для оценки риска.

Третий этап исследовательской работы состоял в анализе свойства накопления металлических элементов в листьях растения оливкового дерева с помощью СЭМ. Для исследования были отобраны пробы почвы с контрольного участка и относительно экологически рискованной территории и проведен их элементный анализ. Результаты анализа показаны на рисунке 3. Из картирования элементного состава почв видно, что в почвенных образцах исследуемых участков, количественное содержание элементного состава различается. Из рисунка 3 видно, что в образцах почв из зоны экологического оптимума содержание металлических элементов ниже по сравнению с зоной экологического риска. Так, в пробе почвы из зоны экологического риска, где произрастает оливковое дерево содержание Al в 11, Mg в 6, а Zn и Cu в 1,5 раза больше по сравнению с экологическим оптимумом. Кроме этого здесь обнаружены тяжелые металлы $\mathrm{Mn}, \mathrm{Ti}$, которые отсутствуют в пробе почвы из экологически оптимальной зоны. Содержание K, Ca, Fe примерно одинаковое в образцах почв с обеих пробных площадок произрастания оливкового дерева.

Также с помощью СэМ было получено графическое изображение картирования элементного состава листьев оливкового дерева, собранных с пробных площадок (рисунок 4). Так, при сравнительном анализе выявлено, что в листьях из экологически оптимальной территории содержание металлических элементов 

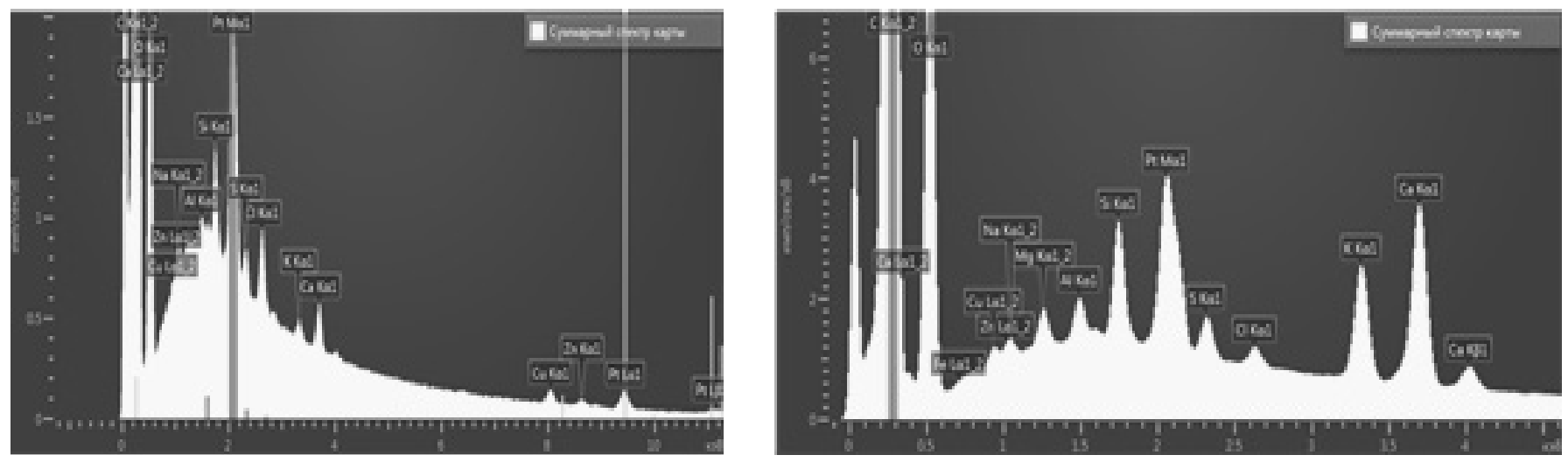

Рис. 4. Картирование элементного состава образцов листьев Olea europea L. при помощи (ЭМ: 1) экологический оптимум 2) экологически загрязненная территория

меньше по сравнению с теми же элементами в листьях из экологически рискованной зоны. В листьях оливкового дерева из экологически рискованной территории накопилось Cu в 1,7, Al в 2,2, Si в 2,4, Zn в 1,5, Cl в 1,7, $\mathrm{Na}$ в 1,6 и S в 1,6 раз больше по сравнению с листьями оливкового дерева, растущего на экологически оптимальной зоне. Mn, Mg və Fe были обнаружены в листьях оливкового дерева из зоны экологического риска, а в листьях из зоны экологического оптимума эти металлы отсутствовали.

Таким образом, определив изменение в онтогенезе стабильного развития растения $O$. europea, можно также дать информацию о физиологических изменениях, происходящих внутри организма. самого растения. Анализ морфометрических показателей, являющийся экономически доступным, простым методом, дает возможность получить информацию для оценки состояния окружающей среды при проведении экологического мониторинга, на основе чего создаются условия для планирования природопользования.

\section{ВывО $\triangle \mathrm{b}$}

Несмотря на достаточную устойчивость оливкового дерева к неблагоприятной окружающей среде, в стрессовых, рискованных условиях организм реагирует, вызывая изменение физиологической стабильности листьев и морфологического признака как проявление фенотипической изменчивости в онтогенезе. Реакция организма в виде изменений морфометрических признаков листьев коррелирует с чувствительностью физиологического состояния внутри листа. Тесть на основе изменения показателей флуктуирующей асимметрии листьев, можно определить закономерность изменения в более мелких структурах внутри организма растения. Другими словами, мы получаем возможность прогнозировать состояние самого организма и также среды, выявляя небольшие изменения, которые еще не привели к полному разрушению организма. Выявленные в экспериментах, как фитоиндикативные, так и ремедиативные свойства Olea europea L., открывают новые возможности для его использования в биомониторинге. В ходе исследований было установлено, что в одной и той же массе листьев в условиях повышенного загрязнения накапливалось больше металлических элементов, чем в зоне экологического оптимума. Это позволяет использовать фиторемедиативные свойства оливкового растения, широко распространенного на Абшероне, в том числе в городе Баку, при проведении биомониторинга и мер для улучшения качества среды.

\section{ЛИТЕРАТУРА}

1. Baker N.R. Chlorophyll fluorescence: a probe of photosynthesis in vivo // Annual Review of Plant Biology. — 2008. — 59. — p.89-113.

2. Belasque J., Gasparoto M.C.G., Marcassa L.G. Detection of mechanical and disease stresses in citrus plants by fluorescence spectroscopy // Applied Optics. 2008. - Vol. 47, no 11. - P. 1922-1926.

3. Bidel, L. Responses of epidermal phenolic compounds to light acclimation: in vivo qualitative and quantitative assessment using chlorophyll fluorescence excitation spectra in leaves of three woody species / L. Bidel, S. Meyer, Y. Goulas [et al.] // Journal of Photochemistry and Photobiology. B. Biology, — 2007. — (2-3), - P. 163-179.

4. Mammadova A.0. Complex assessment of the bioindicative and bioremediative potential of the some plant's species // Annals of Agrarıan Science, — 2010. — (4). - P. 1-8. 
5. Mammadova A.O., Farzaliyev N.F., Mammadova R.N. Environmental Assessment of the Tree Plant Leaves According to their Physiological State and Fluctuating Asymmetry Indices of Morphological Features, Which Widely Spread in Baku // Journal of Ecology of Health \& Environment. — 2017 — Vol. 5. — P. 19-21.

6. Mclver D.C., Fenesh A. Biodiversity monitoring / Proceedings of the Euro MAB2002 Meeting 0ctober 7-11.Ryoma, — 2002. — P. 84-85.

7. Palmer A.R., Strobeck C. (1986) Fluctuating asymmetly measurement, analysis, patterns // Ann. Rev. Ecol. Syst. — 1986. — (17). — P. $391-421$.

8. Thach L.B., Shapcott A., Schmidt S., Critchley C. The 0JIP fast fluorescence rise characterizes Craptophyllum species and their stress responses // Photosynthesis Research, - 2007. - 94(2). - P. 423-436.

9. Tomasevic M.Z, Vukmirovic Z., Rajsic S.M, Tasic M., Stevanovic B. Characterization of trace metal particles deposited on some deciduous tree leaves in an urban area // Chem. - 2004. - 61. - P. 753-760.

10. Захаров В.М. Онтогенез и популяция (стабильность развития и популяционная изменчивость) // Экология. — 2001. — № 3. — С. $177-191$.

11. Кавеленова, Л.М. К методологии экофизиологических исследований листьев древесных растений / Л.М. Кавеленова, Е.В. Малыхина, С.А. Розно, Ю.В. Смирнов // Поволжский экологический журнал. — 2008. — № 3. - С. 200-210.

12. Казимирко Ю.В. Разработка флуорометрических методов оценки состояния фотосинтетического аппарата для биоиндикации среды. Автореф. дисс. канд. биол. наук. - М., - 2006. - 26 с.

13. Мамедова А.О. Биоиндикация качества окружающей среды на основе мутационной и модификационной изменчивости растений / // Цитология и генетика. - 2009. - Т. 43, № 2. - С. 61-64.

14. Мамедова А.О., Фарзалиева Н.М. Оценка загрязненной транспортной среды использованием древесных растений Pinus eldarica Medw. // Becтник Нижневартовского государственного университета. — 2020. — № 1. - С. 134-139.

15. Рубин А.Б. Биофизика фотосинтеза и методы экологического мониторинга // Технология живых систем. — 2005. — Т. 2. - С. 47-68.

(c) Гафарова Беим Таир кызы ( bayimgafarova@gmail.com ),

Мамедова Афет Октай кызы ( m.afet@mail.ru ), Мамедова Роза Назим кызы ( roza2919@mail.ru ).

Журнал «Современная наука: актуальные проблемы теории и практики»

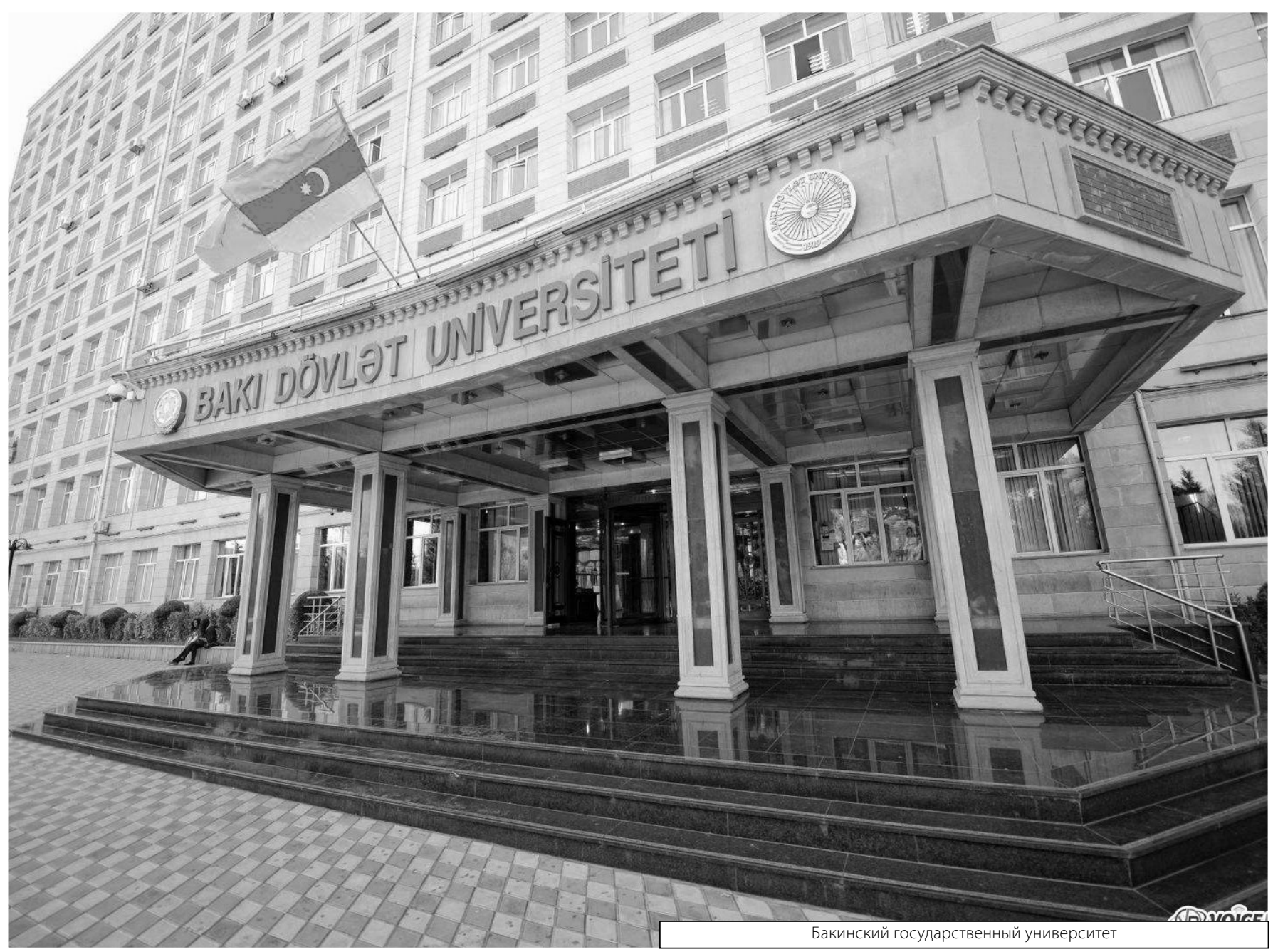

